\title{
TAKAHASHI CONTROLLER WITH CONTINUOUS IDENTIFICATION IN FAST RESPONSE APPLICATION
}

\author{
Plsek Stanislav, Vladimir Vasek \\ Tomas Bata University in Zlin, Faculty of Applied Informatics, Nad Stranemi 4511, 76005 Zlin, Czech Republic
}

\begin{abstract}
The paper describes Takahashi controller with an adaptive system identification in a fast response application and describes hardware design with an 8-bit microcontroller. Takahashi controller is modified PSD controller and due to simple calculation of controller's parameters it can be implemented into the 8-bit microcontroller. The microcontroller was selected from Freescale semiconductor, specifically MC9S08DZ60 which has maximum allowed frequency $40 \mathrm{MHz}$. The identification is based on the least squared recursive method in the beginning of the control process and during the operation at the moment when user changes systems parameters. These are given by the application of the fast response temperature control of soldering tips which are changeable during soldering process. In the first part of the paper the controller is described and in the second part practical aspects of hardware design, such as low power consumption, method how to measure temperature by thermocouple which shares wires with heater and design of $\mathrm{AD}$ converter are described.
\end{abstract}

Keyword: controller; identification; application; microcontroller; fast response
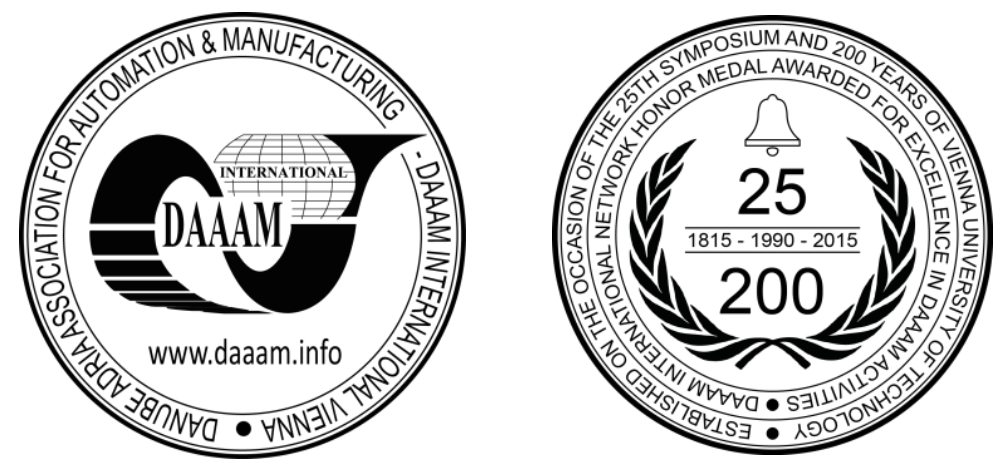

This Publication has to be referred as: Plsek, S[tanislav] \& Vasek, V[ladimir] (2016). Takahashi Controller with Continuous Identification in Fast Response Application, Proceedings of the 26th DAAAM International Symposium, pp.0400-0406, B. Katalinic (Ed.), Published by DAAAM International, ISBN 978-3-902734-07-5, ISSN 1726-9679, Vienna, Austria

DOI:10.2507/26th.daaam.proceedings.054 


\section{Introduction}

PID controllers are used in industry in almost whole sectors [1]. They are known with all their advantages and disadvantages, and also they are used for their favourable price and their easy setting. However, the controllers are not often set properly at ideal value. Nowadays, they can be replaced by their own modifications or by controllers based on algebraic methods. This state is given by a boom of 32-bit cheap microcontrollers.

The PID controllers are effective and have fast response time, but they do not provide enough control quality functions $[3,3]$. They are usually modified [3-5, 7] to improve a stability, the response time without overshoots and for other improvements. Modifications can include filtering of derivative part output, limit the control signal and reduce wind-up effect or add automatic self-tuning functions. These changes usually increase the control quality [1,7], prevent the instabilities or reduce unexpected output values in cases if step-regulation is needed. An example can be in chemical processes (the temperature does not have overshoots) or fast temperature control of soldering tips when the sensitive parts are soldered. This case is commonly necessary when the high-power tips are used for parts assembly on multilayer printed circuit boards with a high thermal capacity. The fast controller response is necessary because the tips can be very fast overheated and in this case the solder degrades faster than normally and flux can be burned.

The main purpose of this paper is firstly inform about the recursive identification together with Takahashi controller and secondly introduce the design of the controller circuit and its verification at normal conditions when the tips are actively used.

\section{Fast response system}

The fast response system is a solder tip which has a built-in heater and a measuring thermocouple. It provides fast response when solder tip is used and almost perfect temperature measurement (it depends on geometry and mass of the tip) [8]. The built-in heater has resistivity $3 \Omega$ approximately, so it provides up to $192 \mathrm{~W}$ thermal energy. If this energy is applied without cooling (by soldering process), the heater overheats tip in a few seconds, burns soldering flux and damage the electric structure (the interrupts itself) and irreversibly oxides the active part of the tip. The tests during the controller modifications proved the temperature can exceed $1000^{\circ} \mathrm{C}$. The value was estimated from the red color of the overheated tip.

Due to the not provided information about the thermocouple parameters, an identification of thermocouple had to be performed. The data were measured by measuring voltage during reheating of the tip by $5 \%$ of power. The tip was encased by a solder alloy Sn95.5Ag3.8Cu0.7 in the first case and by a Sn60Pb40 in the second case. The results are plotted at Fig. 1.

At time approximately $45 \mathrm{~s}$, a pause in the temperature increase can be seen, because there the alloys melted and the heat was consumed for this process. As the result the thermocouple was identified as type E by comparison the tabular voltages of producers.
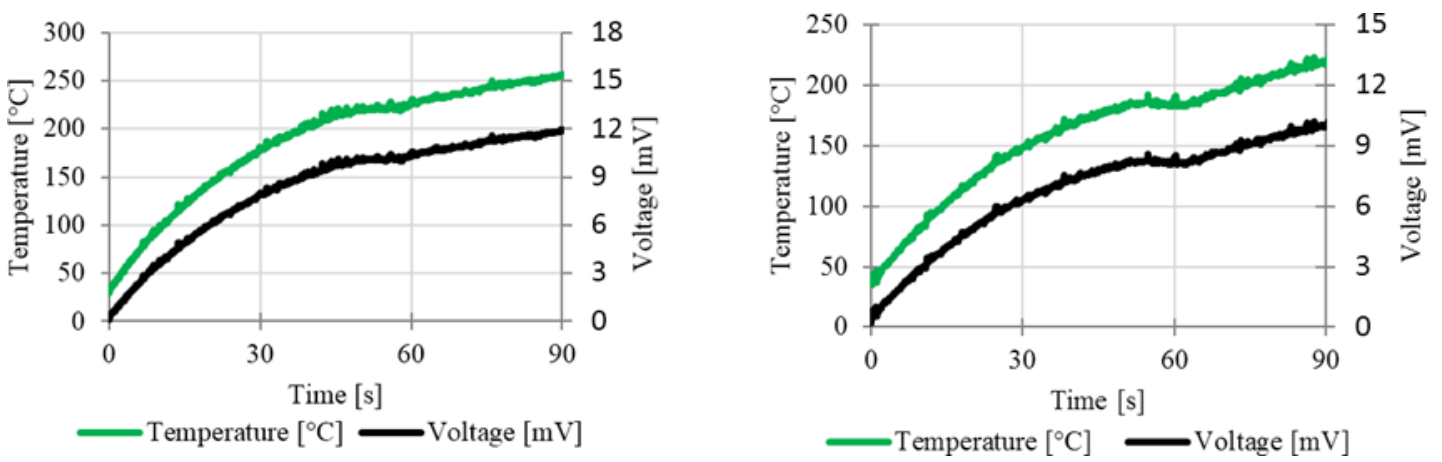

Fig. 1. Thermocouple voltage identification; left $-\mathrm{Sn} 95.5 \mathrm{Ag} 3.8 \mathrm{Cu} 0.7$; right $-\mathrm{Sn} 60 \mathrm{~Pb} 40$

\section{Adaptive identification}

During the solder process of wide range of components (SMT, THT), the tip is usually replaced by another type appropriate for the soldered part and soldered layout (wide spread $\mathrm{Cu}$ areas, tiny terminals). Due to this situation, the adaptive identification was implemented. The algorithm uses the recursive least-square method which does not require inadequate amount of memory space and calculation steps, because it works with two last steps of the controller output and the measured temperature [6,7-13]. As can be seen in Fig. 1, the tips are simple and can be described by the first-order system

$$
G(z)=\frac{b_{1} z^{-1}}{1+a_{1} z^{-1}}
$$


An implicit identification method is described by next equation

$$
\hat{\boldsymbol{\Theta}}=\left(\mathbf{F}^{T} \mathbf{F}\right)^{-1} \mathbf{F}^{T} \mathbf{y}
$$

This equation can be rewritten for $\mathrm{k}-1$ measurements into form

$\hat{\mathbf{\Theta}}(k-1)=\left(\mathbf{F}_{k-1}{ }^{T} \mathbf{F}_{k-1}\right)^{-1} \mathbf{F}_{k-1}{ }^{T} \mathbf{y}(k-1)$

where:

$\mathbf{y}^{T}(k-1)=[y(1) \quad y(2) \quad \ldots \quad y(k-1)]$

is a vector of output variables in the interval $(1, \mathrm{k}-1)$, and

$\hat{\boldsymbol{\Theta}}(k-1)=\left[\begin{array}{llll}\hat{\theta}_{1}(k-1) & \hat{\theta}_{2}(k-1) & \ldots & \hat{\theta}_{r}(k-1)\end{array}\right]$

is vector of optimal estimates of parameter values of transfer function. A matrix

$\mathbf{F}_{k-1}=\left[\begin{array}{cccc}f_{1}(1) & f_{2}(1) & \ldots & f_{r}(1) \\ f_{1}(2) & f_{2}(2) & \ldots & f_{r}(2) \\ \vdots & \vdots & \vdots & \vdots \\ f_{1}(k-1) & f_{2}(k-1) & \ldots & f_{r}(k-1)\end{array}\right]$

is modified matrix F for (k-1) measurements. If $\mathrm{k}$-measurement is done and

$\mathbf{y}(k)=\left[\begin{array}{c}y(k-1) \\ y(k)\end{array}\right]$

is described, the matrix (8)

$\mathbf{F}_{k}=\left[\begin{array}{c}\mathbf{F}_{k-1} \\ \mathbf{\Phi}^{T}(k)\end{array}\right]$

can be written, where

$\boldsymbol{\Phi}^{T}(k)=\left[\begin{array}{llll}f_{1}(k) & f_{2}(k) & \ldots & f_{r}(k)\end{array}\right]$

The vector (10) can be written for k-measured variable

$y(k)=\boldsymbol{\Theta}^{T} \boldsymbol{\Phi}(k)+e(k)$

where $\boldsymbol{\Theta}^{\mathrm{T}}$ is defined as:

$\boldsymbol{\Theta}^{T}=\left[\begin{array}{llll}\theta_{1} & \theta_{2} & \ldots & \theta_{r}\end{array}\right]$

A covariance matrix $\mathrm{C}(\mathrm{k})$ can be defined as

$$
\mathbf{C}(k)=\left[\mathbf{F}_{k-1}^{T} \mathbf{F}_{k-1}+\boldsymbol{\Phi}(k) \mathbf{\Phi}^{T}(k)\right]^{-1}
$$

And it can be written as

$$
\mathbf{C}(k)=\left[\mathbf{C}^{-1}(k-1)+\boldsymbol{\Phi}(k) \mathbf{\Phi}^{T}(k)\right]^{-1}
$$


A general recursive algorithm can be written as

$$
\hat{\boldsymbol{\Theta}}(k)=\hat{\boldsymbol{\Theta}}(k-1)+\mathbf{K}(k)\left[y(k)-\hat{\boldsymbol{\Theta}}^{T}(k-1) \mathbf{\Phi}(k)\right]
$$

where $\mathrm{K}(\mathrm{k})$ is time changing vector of gain and can be written as

$$
\mathbf{K}(k)=\frac{\mathbf{C}(k-1) \mathbf{\Phi}(k)}{1+\mathbf{\Phi}^{T}(k) \mathbf{C}(k-1) \mathbf{\Phi}(k)}
$$

The recursive equation for covariance matrix is

$$
\mathbf{C}(k)=\mathbf{C}(k-1)-\mathbf{C}(k-1) \frac{\boldsymbol{\Phi}(k) \boldsymbol{\Phi}^{T}(k) \mathbf{C}(k-1)}{1+\boldsymbol{\Phi}^{T}(k) \mathbf{C}(k-1) \mathbf{\Phi}(k)}
$$

The vector of parameters $\boldsymbol{\Theta}(\mathrm{k})$ and vector of measurement data $\boldsymbol{\Phi}^{\mathrm{T}}(\mathrm{k})$ can be written for second order transfer function as:

$$
\begin{aligned}
& \boldsymbol{\Theta}^{T}(k)=\left[\begin{array}{ll}
a_{1} & b_{1}
\end{array}\right] \\
& \boldsymbol{\Phi}^{T}(k)=\left[\begin{array}{ll}
-y(k-1) & u(k-1)
\end{array}\right]
\end{aligned}
$$

\section{Takahashi controller}

The modified PID controller was used for system control. This controller which know as Takahashi controller $[9,13]$ calculates the output by the next equation

$$
u(k)=K_{P}\left\{e(k)-e(k-1)+\frac{T_{0}}{T_{I}} e(k)+\frac{T_{D}}{T_{0}}[2 y(k-1)-y(k)-y(k-2)]\right\}+u(k-1)
$$

This controller type eliminates unsuitable aggressive output changes, because the derivative part is modified and does not directly include $\mathrm{e}(\mathrm{k})$. As the derivate part is modified, the proportional and integral part of controller were changed and the final output value can be described by equation

$$
u(k)=K_{P}\left\{-y(k)+y(k-1)+\frac{T_{0}}{T_{I}}[w(k)-y(k)]+\frac{T_{D}}{T_{0}}[2 y(k-1)-y(k)-y(k-2)]\right\}+u(k-1)
$$

The equation (20) is used in microcontroller and its parameters are calculated equations (21 - 23).

$$
\begin{aligned}
K_{P} & =0.6 K_{P K}\left(1-\frac{T_{0}}{T_{K}}\right) \\
T_{I} & =\frac{K_{P} T_{K}}{1.2 K_{P K}} \\
T_{D} & =\frac{3 K_{P K} T_{K}}{40 K_{P}}
\end{aligned}
$$

Where $T_{0}$ is sampling period of controller and identification part, $T_{K}$ is critical period and $K_{P K}$ is critical gain. The $T_{K}$ and the $\mathrm{K}_{\mathrm{PK}}$ directly depend on the identified system and they are calculated by

$$
\begin{aligned}
& K_{P k}\left(T_{0}\right)=\frac{1-a_{1}}{b_{1}} \\
& T_{k}\left(T_{0}\right)=2 T_{0}
\end{aligned}
$$

\section{Controller hardware}

The controller was implemented into 8-bit microcontroller MCS08DZ60 by Freescale semiconductor. This microcontroller has sufficient power, because the core can run at $40 \mathrm{MHz}$ [14]. It has 4kb RAM, 60kb flash memory and 
$2 \mathrm{~kb}$ EEPROM. In the EEPROM are stored constants of controllers and last two steps of the identification process (automatically saved at switch off time) and user settings (temperatures, sleep and hibernation time and power on hours).

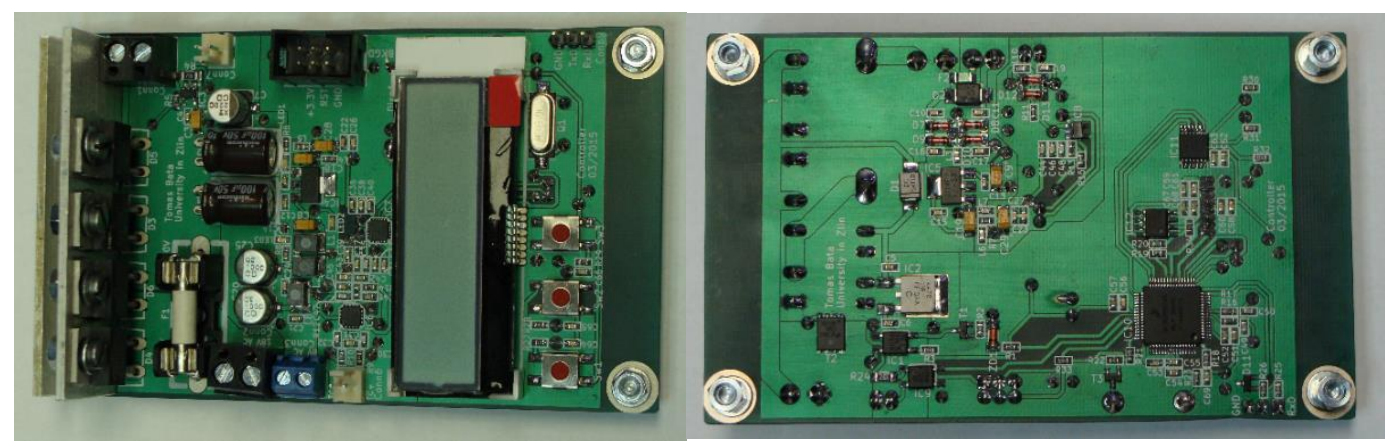

Fig. 2. Top and bottom side of the controller

The measurement of the low signal of thermocouple is ensured by instrumentation amplifier AD8231 with digitally setting of gain in steps 1-24-8-16-32-64-128 [15]. The amplified voltage is filtered by two stage low-pass filters. The first at $757 \mathrm{~Hz}$ is connected before the instrumentation amplifier and the second filter, type Sallen-key at $144 \mathrm{~Hz}$, is inserted at the input of AD converter. The AD converter is fast SAR, 16-bit AD7682 [16], which can work with internal reference $2.5 \mathrm{~V}, 5 \mathrm{~V}$ or external reference. With $250 \mathrm{ksps}$ and $38.17 \mu \mathrm{V}$ resolution it is appropriate, because the system sample 16 time during the short period when the power supply sine crosses the zero value. The average value is used by the controller. That method was chosen to eliminate inaccurate measurement, because the heater shares wires with the thermocouples and the current through wires and connectors causes the increased voltage which is measured and it out of amplifier range.

The electrical connection of input circuits is shown at the fig. 3. It includes noise suppression circuits, filters and $\mathrm{AD}$ converter for two systems of tips (two tips or one tweezer can be used). The power supply filtration capacitors for ADC and amplifiers are not shown.

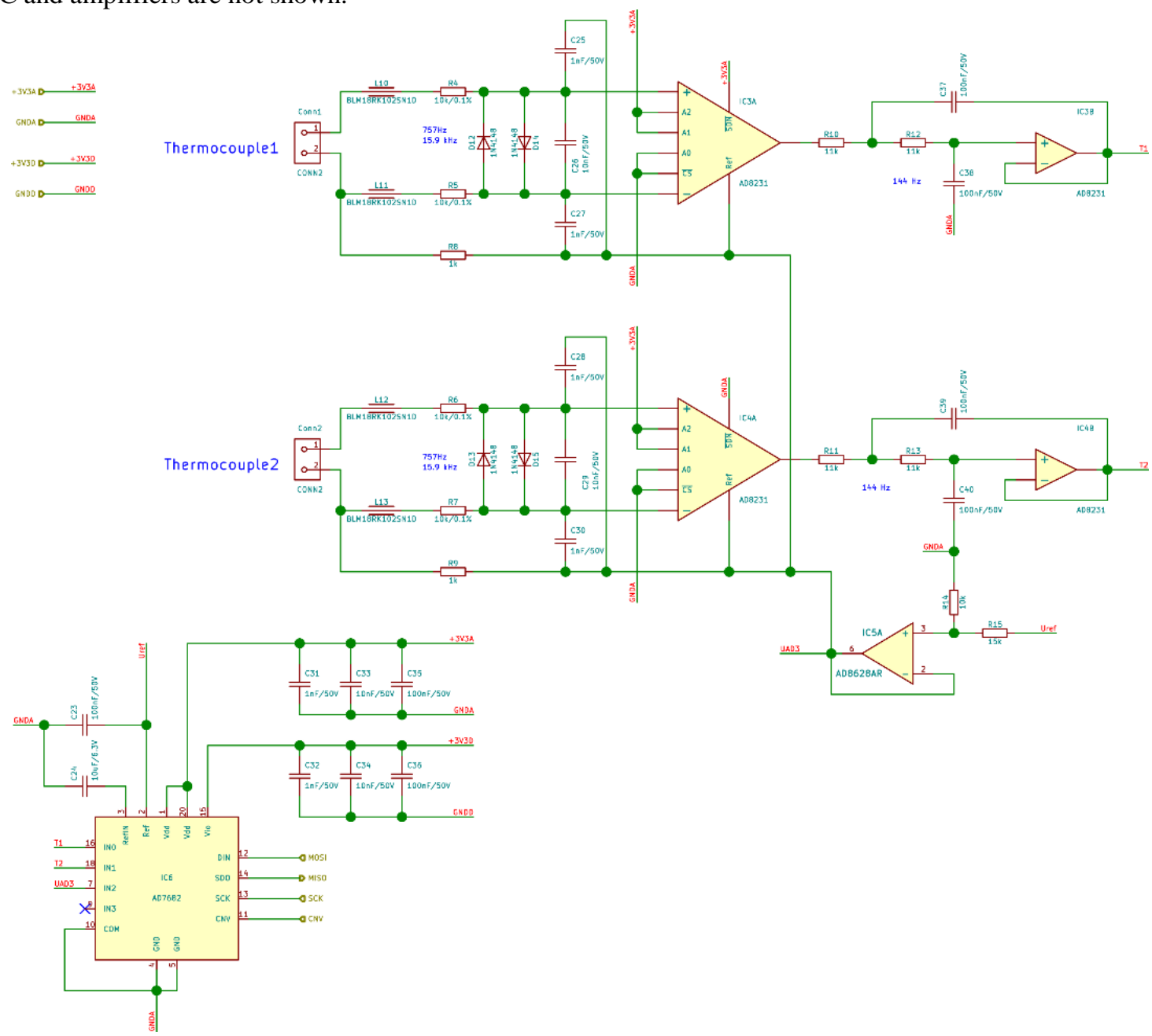

Fig. 3. Analog part for two inputs 


\section{Design verification}

The controlled board with Takahashi PID controller and adaptive identification were tested and verified on soldering tips at changing conditions (ambient temperature, cooling by air flow, up to 5 type of tips, different electronic parts and printed circuit board layouts).

As the first step, tip responses were measured and the preliminary system identification was proceeded. As the second step the controller were verified during the automatic identification which used the parameters get at the first point as a starting values for identification.

The controller verification was performed with period $\mathrm{T}_{0}=100 \mathrm{~ms}$, and the PWM period was selected a $\mathrm{T}_{\mathrm{PWM}}=20 \mathrm{~ms}$ (period of power supply line). The shortest impulse value was set to $10 \mu \mathrm{s}$.

At fig. 4 the responses for $\mathrm{u}=5 \%$ and $\mathrm{u}=10 \%$ are plotted. The first-order system were calculated by numerical method and result are written below. Equation (26) correspond to $\mathrm{u}=5 \%$ and equation $(27)$ to $\mathrm{u}=10 \%$.

$$
\begin{aligned}
& G(s)=\frac{221.3}{30.3 s+1} \\
& G(s)=\frac{370.6}{22.6 s+1}
\end{aligned}
$$
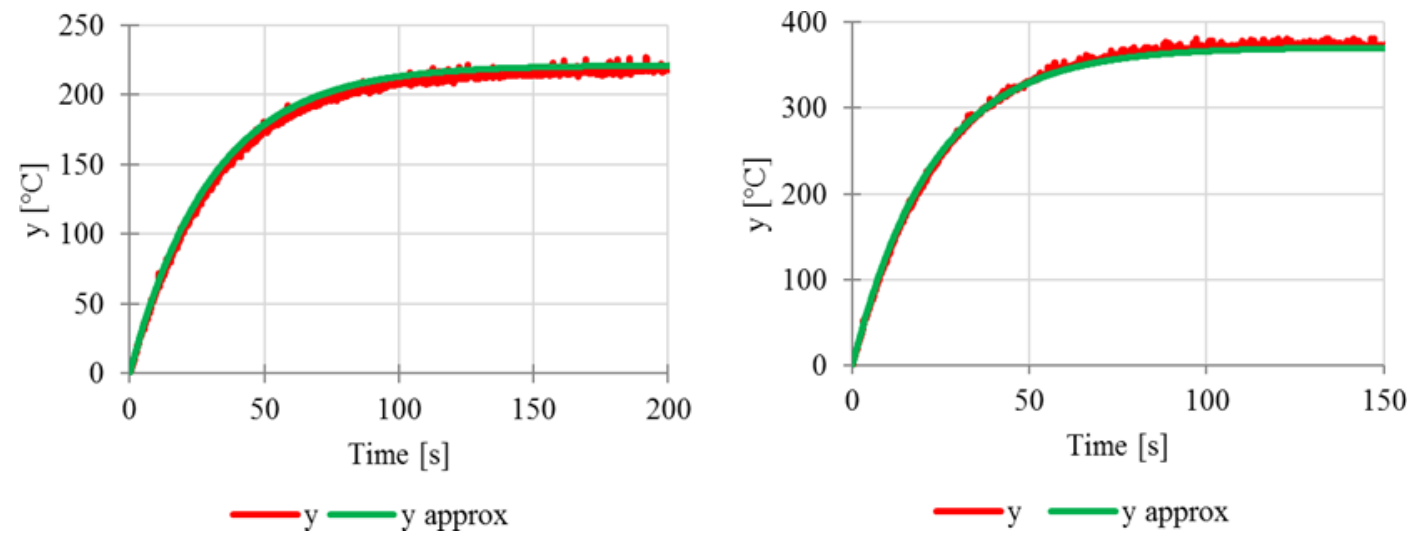

Fig. 4. the identification at $\mathrm{u}=5 \%$ and $\mathrm{u}=10 \%$

The verification of the controller is shown at Fig. 5. Two step changes are measured with different start conditions. The first step simulated the previous sleep function when $100^{\circ} \mathrm{C}$ of tip was set. The second step simulated start of soldering tip from temperature about $30^{\circ} \mathrm{C}$. As can be seen, the overshoots did not occurred, although the set temperature were achieve almost immediately. The falling temperature between two steps at graph is part when the tip were cooled at room temperature.

Due to the small noise in measured value, the controller output had small rapid changes. This problem is probably caused by insufficient filtering of noisy signal and can be removed by improved filtration for example by recalculated low-pass filter or added numerical filter.

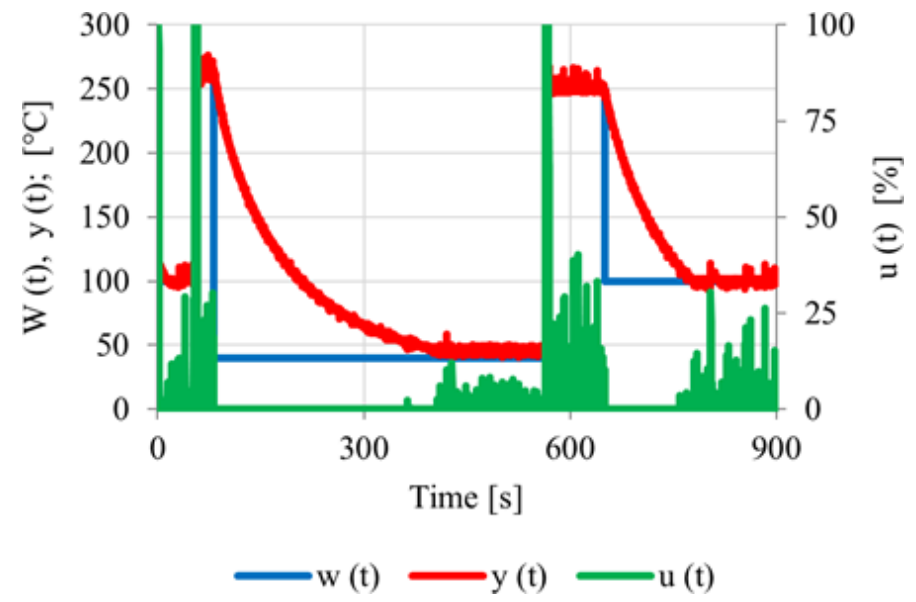

Fig. 5. Controller verification 


\section{Conclusion}

The article describes the application of adaptive identification and Takahashi controller in process of fast temperature control. The application was designed for 8-bit microcontroller MC9S08DZ60. The circuit was designed universally for almost types of thermocouples which are built-in tip heaters. It is provided by instrumentation amplifier and also without special monolithic integrated circuit which are predestined for specific type.

The design of Takahashi controller, recursive identification and electronic circuits were verified and as can be seen, it is usable for common applications after minor changes in filtration. The overshoots are minimal without effect on solder, because the temperature is measured directly inside the heater. During the soldering process were not observed the problems with overheating or low temperature except the tiniest tip together soldered large area of copper layer.

\section{Acknowledgements}

This work was supported by the Ministry of Education, Youth and Sports of the Czech Republic within the National Sustainability Programme project No. LO1303 (MSMT-7778/2014) and by Internal Grant Agency of Tomas Bata University in Zlin, IGA/FAI/2015/032.

\section{References}

[1] A. Theorin, T. Hägglund. Derivative backoff: The other saturation problem for PID controllers. Journal of Process Control. 2015, 33: 155-160. DOI: 10.1016/j.jprocont.2015.06.008. ISSN 0959-1524. Available from: http://linkinghub.elsevier.com/retrieve/pii/S0959152415001353

[2] P. Klan, PI controllers with appropriate setting [PI regulátory s dobrým nastavením], Automa: magazine for automation and control engineering. Issue. 6, 2005. ISSN: 1210-9592

[3] K. Åström, J. Karl, T. Hägglund. PID controllers. Second ed., Research Triangle Park, N.C.: International Society for Measurement and Control, 1995. ISBN 15-561-7516-7

[4] K. Åström, J. Karl, R. M. Murray, Feedback systems. Version v2.10b. Princeton: Princeton University Press, 2009. ISBN 978-0-691-13576-2

[5] J. Balátě, Automatic control [Automatické řízení]. Second ed., Prague: BEN - technical literature, 2004. ISBN 978-80-7300-148-3

[6] S. Plsek, Application of adaptive dead-beat controller in drying Process. Procedia Engineering, 2015, No. 100, p. 756-764. ISSN 1877-7058

[7] A. O'Dwyer, Handbook of PI and PID controller tuning rules, 3rd ed., London: Imperial College Press, 2009. ISBN 978-1-84816-242-6

[8] Jaume Benet Canals. JBC INDUSTRIAS S.A. Electric soldering iron. patent, EP 1086772 A2. Granted 28.3.2001.

[9] V. Bobál, Adaptive and predictive control [Adaptivní a prediktivní řízení]. Zlin: Tomas Bata University in Zlin, 2008, 134 p. ISBN 978-80-7318-662-3.

[10] V. Bobál, Systems identification [Identifikace systémů]. Zlin: Tomas Bata University in Zlin, 2009, 128 p. ISBN 978-80-7318-888-7.

[11] P. Navrátil, Time-continuous identification methods for design of self-tuning controllers: dissertation thesis. Zlin, 2007. 119 p.

[12] V. Bobál, Practical aspects of self-tuning controllers: algorithms and implementations [Praktické aspekty samočinně se nastavujících regulátorů : algoritmy a implementace]. Brno: VUTIUM, 1999, 242 p. ISBN 80-214129-92.

[13] P. Dostálek, J. Dolinay, V. Vašek and L. Pekař, "Self-tuning digital PID controller implemented on 8-bit Freescale microcontroller", International Journal of Mathematical Models and Methods in Applied Sciences. 2010, vol. 4, iss. 4, p. 274-281. ISSN 1998-0140

[14] Freescale Semiconductor. MC9S08DZ60 datasheet [online]. 2008. Freescale Semiconductor, Inc.: Freescale Semiconductor Literature Distribution Center, 2008 [cit. 2015-09-30]. Available on WWW: http://www.freescale.com

[15] Analog Devices. Zero Drift, Digitally Programmable Instrumetation Amplifier AD8231. Datasheet [online]. 2011. Analog Devices Inc. [cit 2015-09-30]. Available on WWW: http://www.analog.com

[16] Analog Devices. 16-bit, 4channel/8-channel, 250ksps PulSAR ADC AD7682/AD768. Datasheet [online]. 2015. Analog Devices Inc. [cit 2015-09-30]. Available on WWW: http://www.analog.com 